Check for updates

Cite this: Chem. Sci., 2019, 10, 2326

๑ All publication charges for this article have been paid for by the Royal Society of Chemistry

Received 8th October 2018

Accepted 18th December 2018

DOI: $10.1039 / \mathrm{c} 8 \mathrm{sc} 04470 \mathrm{~h}$

rsc.li/chemical-science

\section{Synthesis and structural features of thiophene- fused analogues of warped nanographene and quintuple helicene $\uparrow$}

\author{
Hsing-An Lin, ${ }^{\text {ab }}$ Kenta Kato, ${ }^{b}$ Yasutomo Segawa, (D) *ab Lawrence T. Scott (D) ${ }^{c}$ \\ and Kenichiro Itami (iD *abd
}

\begin{abstract}
Thiophene-fused analogues of warped nanographene (WNG) and quintuple helicene (QH) were synthesized via a three-step $\pi$-extension of corannulene. Similar to the synthetic route to WNG, five hexagons and five heptagons were generated by a Scholl reaction of pentakis(thienylphenyl)corannulene to form pentathiaWNG. In contrast, decathiaWNG could not be obtained from pentakis(thienylthienyl) corannulene, and instead decathiaQH was generated from the photocyclization of the precursor. X-ray crystallography of the products revealed their conformations and packing modes in the solid state. The configurational features of decathiaQH were further examined by DFT calculations. The absorption and fluorescence spectra of the sulfur-containing WNG and $Q H$ were shifted relative to those of the corresponding sulfur-free analogues.
\end{abstract}

\section{Introduction}

Nonplanar polycyclic aromatic hydrocarbons (PAHs) are an important class of $\pi$-conjugated materials. Various curved architectures of PAHs have been investigated in order to endow such PAHs with new properties. ${ }^{\mathbf{1 - 4}}$ The field of negatively curved PAHs is growing rapidly, in large part because the saddleshaped $\pi$-skeletons of such compounds reduce molecular aggregation compared to their flat analogues. They also often exhibit dynamic conformations and unique physical properties. Negatively curved PAHs generally embed a heptagon or an octagon in fused hexagonal $\pi$-skeletons of $e . g$. didehydrohexa[7] circulene and its analogues, ${ }^{5,6}[7]$ circulene, $^{7}$ and [8]circulene. ${ }^{8}$ Recently, $\pi$-extended [7]circulene and [8]circulene derivatives have been synthesized, which include tetrabenzo[7]circulene, ${ }^{9}$ tetrabenzo[8]circulene and its derivatives, ${ }^{10-12}$ as well as a giant twisted nanographene with an [8]circulene as the core structure. ${ }^{13}$ Furthermore, embedding two heptagons in the fused $\pi$ system can lead to even more exotic structures of negatively curved PAH such as $[7,7]$ circulene $^{\mathbf{1 4}}$ and new saddle-shaped PAHs. ${ }^{15,16}$

aJST-ERATO, Itami Molecular Nanocarbon Project, Nagoya University, Chikusa, Nagoya, 464-8602, Japan.E-mail: Itami@chem.nagoya-u.ac.jp; ysegawa@nagoya-u.jp ${ }^{b}$ Graduate School of Science, Nagoya University, Chikusa, Nagoya, 464-8602, Japan 'Merkert Chemistry Center, Boston College, Chestnut Hill, Massachusetts 02467-3860, USA

${ }^{d}$ Institute of Transformative Bio-Molecules (WPI-ITBM), Nagoya University, Chikusa, Nagoya, 464-8602, Japan

$\dagger$ Electronic supplementary information (ESI) available. CCDC 1865257-1865259. For ESI and crystallographic data in CIF or other electronic format see DOI: $10.1039 / \mathrm{c} 8 \mathrm{sc} 04470 \mathrm{~h}$
We have previously reported a warped nanographene (WNG; Fig. 1) bearing five heptagons, ${ }^{17}$ which exhibits a saddle-shaped structure, high solubility, intense fluorescence, and reversible multi-redox properties. We have also elucidated the reaction pathway for the formation of WNG, which provides the details of heptagon formation with a corannulene core during the Scholl reaction. ${ }^{18}$ More recently, we have used a sequential $\mathrm{C}-\mathrm{H}$ functionalization and cross-coupling reaction for the functionalization of WNG in order to develop a water-soluble

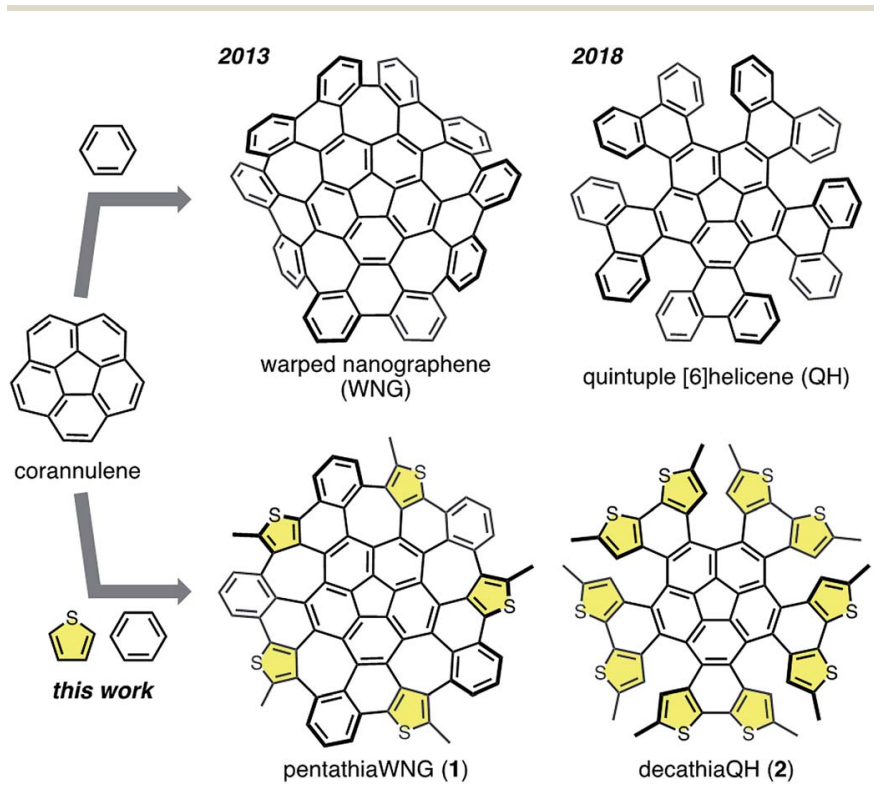

Fig. 1 Warped nanographene, quintuple [6]helicene, and their thiophene-fused analogues 1 and 2 . 
WNG. ${ }^{19}$ Given the long fluorescence lifetime in water, the excellent photostability, and the low cytotoxicity, we were able to demonstrate the use of water-soluble WNG in live-cell imaging and photo-induced cell death.

Fusing thiophene into the $\pi$-conjugated skeleton of PAH affects its electronic and optical properties as well as its structure. Replacing benzene with thiophene in the curved $\pi$ system of [8]circulene affects its band gap and the aromaticity. However, the thiophene-fused [8]circulene analogue forms a planar structure. ${ }^{2021}$ Similar results were observed for [7] circulene when thiophenes are fused. ${ }^{22}$ Yet, fusing thiophene into the core structure of negatively curved PAHs while retaining their negatively curved structure remains synthetically challenging.

Multiple helicenes and their thiophene-fused analogues (multiple thiahelicenes) also constitute an important class of nonplanar $\pi$-systems. ${ }^{23}$ Their unusual twisted conformations and three-dimensional intermolecular interactions have spurred substantial scientific interest to study their dynamic structures as well as their chiroptical and electronic properties. ${ }^{24-28}$ Several synthetic strategies have been developed for the construction of multiple (thia)helicenes, ${ }^{29-32}$ and these (thia) helicenes have found promising applications in e.g. asymmetric catalysis, electronic devices, and liquid crystals. ${ }^{33-37}$

Herein, we report the synthesis of thiophene-containing WNG and quintuple helicenes. PentathiaWNG (1; Fig. 1) was successfully obtained from the Scholl reaction of a pentakis(thienylphenyl)corannulene, and its saddle-shaped structure was confirmed by X-ray crystallography. In contrast, decathiaQH (2; Fig. 1) was obtained instead of the expected decathiaWNG from the same treatment of a pentakis(thienylthienyl) corannulene. As 2 is a thiophene-containing analogue of quintuple [6] helicene (QH; Fig. 1) ${ }^{38}$ the structural features of 2 were investigated by density functional theory (DFT) calculations.

\section{Results and discussion}

\section{Synthesis and structure}

PentathiaWNG (1) was obtained from a sequential crosscoupling reaction and cyclodehydrogenation as shown in Scheme 1a. Initially, pentakis(Bpin)corannulene $(3)^{39}$ was coupled with 2-(2-bromophenyl)-5-methylthiophene (4) via a Pdcatalyzed Suzuki-Miyaura coupling to afford 5 in $90 \%$ yield. Subsequently, the oxidative cyclodehydrogenation reaction (Scholl reaction) of $\mathbf{5}$ using $p$-chloranil and methanesulfonic acid $(\mathrm{MsOH})$ generated 1 in $40 \%$ yield. Scholl reactions of the analogue in which the methyl groups of $\mathbf{5}$ were replaced with hydrogen atoms resulted in the formation of a complex mixture, which suggests that the methyl groups might work as efficient protecting groups for the highly reactive $\alpha$-positions of the thiophene moieties. Single crystals of 1 were obtained by recrystallization from 1,1,2,2-tetrachloroethane, and the structure of 1 was confirmed by X-ray crystallography (Scheme 1b). PentathiaWNG 1 exhibits a saddle-shape structure due to the presence of five heptagons. The packing mode of $\mathbf{1}$ in the crystalline state is characterized by segregated stacks of pairs of enantiomers. Neither significant sulfur-sulfur interaction nor $\pi-\pi$ stacking was found. The dynamic behavior of 1 was examined using DFT calculations at the B3LYP/6-31G(d) level of theory in order to estimate the racemization barrier. The calculated racemization energy of $1\left(15.8 \mathrm{kcal} \mathrm{mol}^{-1}\right)$, which is slightly lower than that of WNG $\left(18.9 \mathrm{kcal} \mathrm{mol}^{-1}\right),{ }^{17}$ indicates that 1 racemizes rapidly in solution at ambient temperatures and that the separation of the enantiomers of 1 could be quite difficult.

We also attempted to prepare decathiaWNG (8), which bears ten thiophene moieties, via the same synthetic strategy as that used for 1. Compound 7 was obtained in $74 \%$ yield from the coupling reaction of 3 and 3-bromo-5,5'-dimethyl-2,2'-bithiophene (6), ${ }^{40}$ and 7 was subsequently subjected to a Scholl reaction with $p$-chloranil and $\mathrm{MsOH}$, which resulted in unidentified mixtures instead of $\mathbf{8}$. Thus, we changed our synthetic strategy to a stepwise cyclodehydrogenation of 7 , i.e., a sequential photocyclization and Scholl reaction. The photocyclization of 7 was carried out at room temperature under argon atmosphere for 2 days. The targeted thiophenecontaining quintuple helicene (2) was obtained in $20 \%$ yield. ${ }^{\mathbf{4 1}}$ The ${ }^{1} \mathrm{H}$ NMR spectrum of 2 showed five singlets in the aromatic region (6.7-8.3 ppm), which correspond to the hydrogen atoms at the $\beta$-positions of the thiophene moieties. This result indicated that 2 exhibits $C_{2}$-symmetry in solution rather than a $D_{5^{-}}$ symmetric propeller-shaped structure. An X-ray crystallographic analysis revealed that $\mathbf{2}$ was obtained as a racemic mixture of conformer $\mathbf{D}$ (Fig. 2a) and its enantiomer. Upon heating in 1,1,2,2-tetrachloroethane- $d_{2}$ to $70{ }^{\circ} \mathrm{C}$ for 3 days, the thusobtained 2 gradually decomposed, and insoluble solids were formed. The Scholl reaction of 2 was attempted, using $p$-chloranil and $\mathrm{MsOH}$; however, compound $\mathbf{8}$ was not found in the reaction mixture.

\section{Conformational studies of 2}

To further understand the conformations of 2 , we carried out DFT calculations for the analysis of its structures and dynamic behavior. Considering the combinations of the helicity of each dithia[6]helicene moiety ( $P$ or $M$; Fig. 2a), eight stereoisomers, including four pairs of enantiomers of $\mathbf{2}[\mathbf{A}(P P P P P), \mathbf{B}(P P P P M)$, $\mathbf{C}(P P P M M)$, and $\mathbf{D}(P P M P M)$, as well as their enantiomers ( $\mathbf{A}^{*}-$ $\left.\mathbf{D}^{*}\right)$ ], were obtained as local minima, similar to the previously reported $\mathbf{Q H} .^{38}$ Given the rapid bowl-inversion of the corannulene moieties, it can be expected that $\mathbf{A}$ and the other stereoisomers (B-D) afford NMR spectra that are characterized by $D_{5}$ - and $C_{2}$-symmetry, respectively. The $C_{5}$-symmetric structure $\mathbf{A}$ emerged as the most stable conformation, and the Gibbs free energy values of $\mathbf{B}, \mathbf{C}$, and $\mathbf{D}$ relative to that of $\mathbf{A}$ are 2.9, 7.0, and $2.1 \mathrm{kcal} \mathrm{mol}^{-1}$, respectively. Ten transition states (TSs), which correspond to the chiral inversion for each dithia[6]helicene moiety, were identified and the conversion barrier from $\mathbf{D}$ to $\mathbf{A}$ of $33.6 \mathrm{kcal} \mathrm{mol}^{-1}$ was calculated (Fig. 2b). According to these calculations, it can be concluded that conformer $\mathbf{D}$ and its enantiomer $\left(\mathbf{D}^{*}\right)$ were formed kinetically by the photocyclization reaction at ambient temperature without conformational change due to the relatively high conversion barrier. It is characteristic of some multiple helicenes that relatively 
a
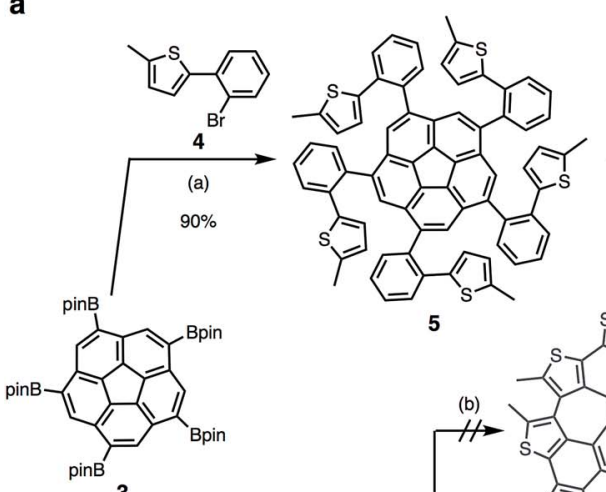

$\underset{40 \%}{\stackrel{\text { (b) }}{\longrightarrow}}$

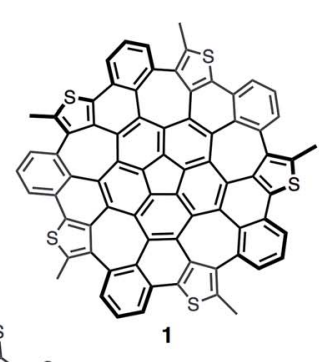

b

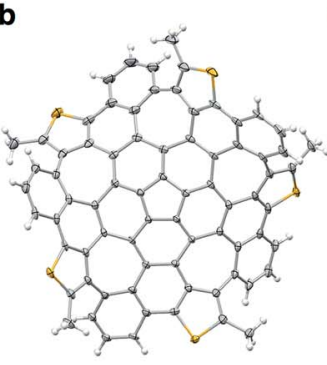

d

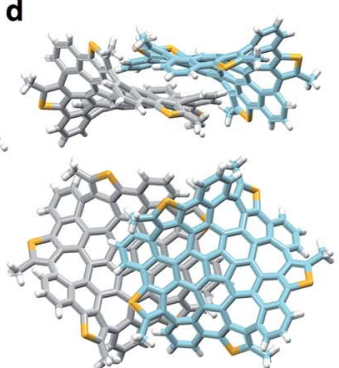

C
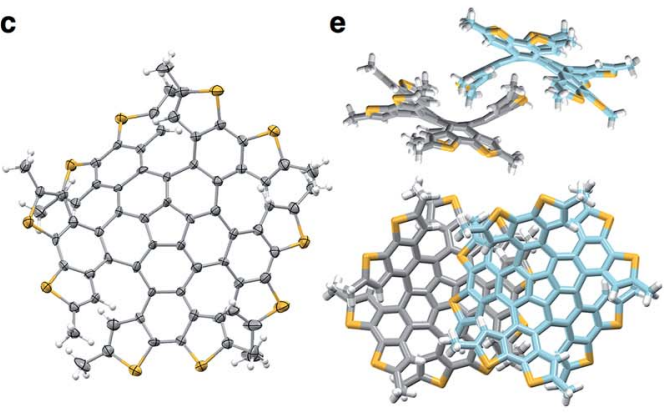

Scheme 1 (a) Synthesis of 1 and 2. Reaction conditions: (a) 4or 6 (8-10 equiv.), $\mathrm{Pd}_{2}(\mathrm{dba})_{3} \cdot \mathrm{CHCl}_{3}\left(0.2\right.$ equiv.), SPhos (0.4 equiv.), $\mathrm{Cs}_{2} \mathrm{CO}_{3}(10$ equiv.), toluene $/ \mathrm{H}_{2} \mathrm{O}=2: 1,80^{\circ} \mathrm{C}, 48 \mathrm{~h}$; (b) $p$-chloranil (10 equiv.), $\mathrm{MsOH} / \mathrm{CH}_{2} \mathrm{Cl}_{2}=1: 10,0{ }^{\circ} \mathrm{C}, 1.5 \mathrm{~h}$; (c) $\mathrm{I}_{2}$ (5 equiv.), propylene oxide (100 equiv.), $h \nu$, toluene, r.t., 48 h. Bpin = pinacolatoboryl, dba = (dibenzylidene)acetone; SPhos $=2$-dicyclohexylphosphino-2', $6^{\prime}$-dimethoxybiphenyl. ( $b$ and c) ORTEP of 1 (b) and 2 (c) with 50\% thermal probability. (d and e) Packing structure of 1 (d) and 2 (e); side (top) and top view (bottom). Solvent molecules are omitted for clarity.
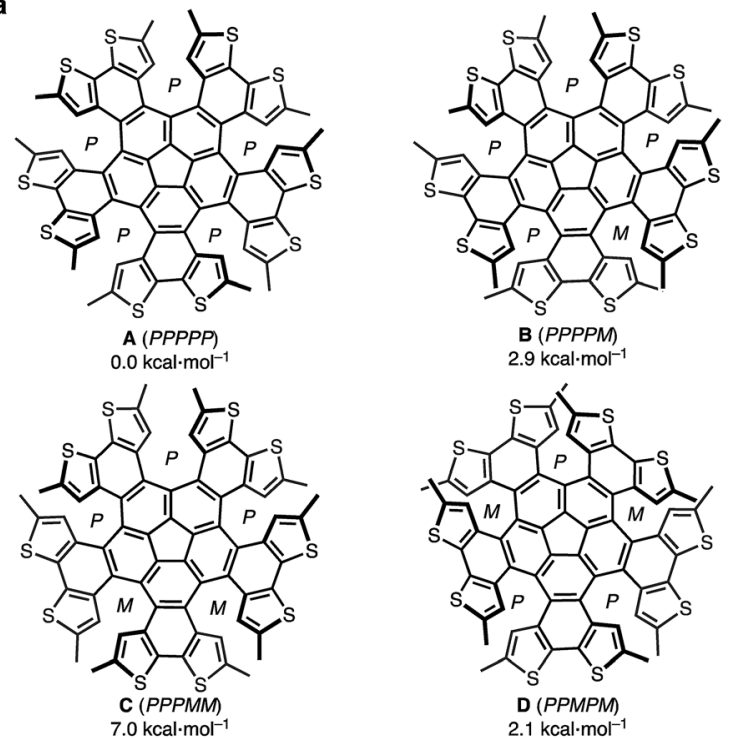

b

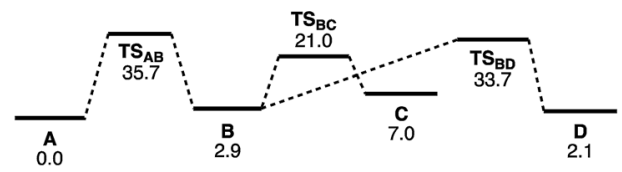

Fig. 2 (a) Optimized conformers of 2 (A-D) with the helicity of the helicene moieties $(P$ or $M)$ and the Gibbs free energy values $(\Delta G / \mathrm{kcal}$ $\mathrm{mol}^{-1}$ ) relative to that of $A$ calculated at the B3LYP/6-31G(d) level of theory. (b) Energy diagram of the ground states and transition states of $2\left(\Delta \mathrm{G} / \mathrm{kcal} \mathrm{mol}^{-1}\right)$. unstable conformations are formed at low or ambient temperature. ${ }^{25,30,42-44}$

\section{Photophysical properties}

The UV-Vis absorption and fluorescence properties of $\mathbf{1}$ and 2 were investigated, as summarized in Fig. 3. The absorption maximum of 1 appears at $426 \mathrm{~nm}$ with two shoulders at $460 \mathrm{~nm}$ and $485 \mathrm{~nm}$; the maximum absorption of 1 is slightly redshifted compared with that of WNG (Fig. S3†). The emission spectra of 1 displays one maximum emission at $490 \mathrm{~nm}$ with two shoulders at $520 \mathrm{~nm}$ and $558 \mathrm{~nm}$. The fluorescence

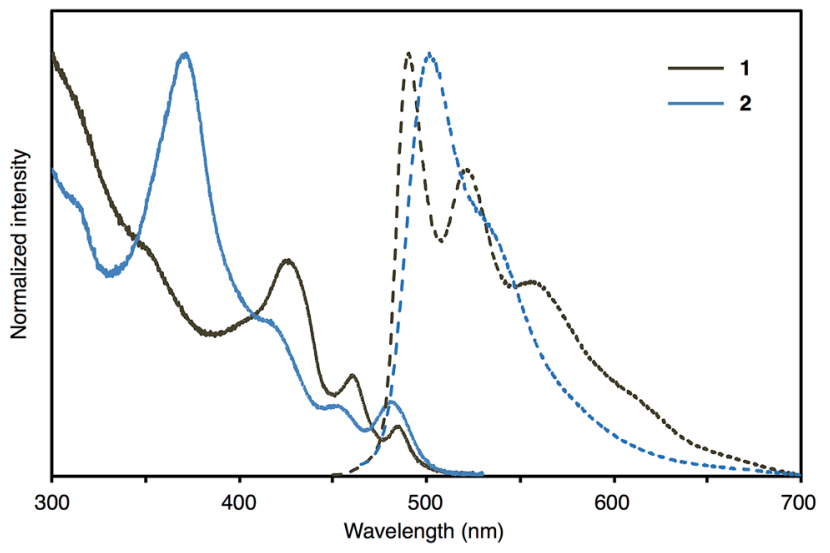

Fig. 3 UV/Vis absorption spectra (solid line) and fluorescence spectra (broken line) of 1 (gray) and 2 (blue) in $\mathrm{CH}_{2} \mathrm{Cl}_{2}$. The fluorescence spectra were obtained by irradiation at $445 \mathrm{~nm}$ (1) and $380 \mathrm{~nm}$ (2). 
quantum yield of $\mathbf{1}\left(\Phi_{\mathrm{F}}=0.08\right)$ is much lower than that of WNG $\left(\Phi_{\mathrm{F}}=0.26\right) .{ }^{17}$ The absorption maximum of 2 appears at $370 \mathrm{~nm}$ with three shoulders at $417 \mathrm{~nm}, 453 \mathrm{~nm}$ and $481 \mathrm{~nm}$. The emission spectra of 2 displays one maximum emission at $502 \mathrm{~nm}$ with one shoulder at $534 \mathrm{~nm}$. Both maximum absorption and emission of 2 exhibit a hypsochromic shift compared to that of $\mathbf{Q H}$. The fluorescence quantum yield of 2 is low $\left(\Phi_{\mathrm{F}}=\right.$ $0.02)$ and similar to that of $\mathbf{Q H}\left(\Phi_{\mathrm{F}}=0.03\right) .{ }^{38}$ According to DFT calculation, HOMO energy of 1 and $2(-5.09 \mathrm{eV}$ and $-4.97 \mathrm{eV})$ are higher than those of pristine WNG and QH $(-5.11 \mathrm{eV}$ and $-5.28 \mathrm{eV}$ ) reflecting the electron donation effect of the thiophene moieties (Fig. S7†).

\section{Conclusions}

We have successfully synthesized WNG analogue 1, which bears five fused thiophenes in the WNG structure, and quintuple helicene 2, which bears ten thiophene moieties. The synthesis of 1 was achieved by a Scholl reaction using $p$-chloranil and methanesulfonic acid. The crystal structure of $\mathbf{1}$ and the corresponding DFT calculations reveal that 1 exhibits negative curvature and flexible conformations owing to the presence of five heptagons. The photophysical properties of $\mathbf{1}$ are characterized by broad emission signals with low quantum yield compared to its all-benzene analogue (WNG). The synthesis of 2 was accomplished by a photocyclization reaction, and a theoretical study was conducted to investigate the dynamic conformations of 2. This study identified four pairs of enantiomers (A$\mathbf{D}$ and $\left.\mathbf{A}^{*}-\mathbf{D}^{*}\right)$ as ground states and ten transition states between these ground states. The developed synthetic strategies may provide guidelines for the design and synthesis of other heteroatom-containing nonplanar $\pi$-systems.

\section{Conflicts of interest}

There are no conflicts to declare.

\section{Acknowledgements}

This work was supported by the ERATO program from JST (JPMJER1302 to K. I.), the Funding Program for KAKENHI from MEXT (JP16K05771 to Y. S.), a grant-in-aid for Scientific Research on Innovative Areas " $\pi$-Figuration" from JSPS (JP17H05149 to Y. S.), the Noguchi Institute (to Y. S.), and the US National Science Foundation (CHE-1149096 to L. T. S.). K. K. thanks IGER Program in Green Natural Sciences, Nagoya University and the JSPS fellowship for young scientists. Calculations were performed using the resources of the Research Center for Computational Science, Okazaki, Japan. ITbM is supported by the World Premier International Research Center Initiative (WPI), Japan.

\section{Notes and references}

1 M. Stępień and M. A. Majewski, Angew. Chem., Int. Ed., 2019, 58, 86 .
2 M. Rickhaus, M. Mayor and M. Juríček, Chem. Soc. Rev., 2017, 46, 1643-1660.

3 Y. Segawa, H. Ito and K. Itami, Nat. Rev. Mater., 2016, 1, 15002.

4 A. Narita, X.-Y. Wang, X. Feng and K. Müllen, Chem. Soc. Rev., 2015, 44, 6616-6643.

5 P. J. Jessup and J. A. Reiss, Tetrahedron Lett., 1975, 16, 14531456.

6 A. Pradhan, P. Dechambenoit, H. Bock and F. Durola, J. Org. Chem., 2013, 78, 2266-2274.

7 K. Yamamoto, T. Harada, M. Nakazaki, T. Naka, Y. Kai, S. Harada and N. Kasai, J. Am. Chem. Soc., 1983, 105, 71717172.

8 C.-N. Feng, M.-Y. Kuo and Y.-T. Wu, Angew. Chem., Int. Ed., 2013, 52, 7791-7794.

9 X. Gu, H. Li, B. Shan, Z. Liu and Q. Miao, Org. Lett., 2017, 19, 2246-2249.

10 R. W. Miller, S. E. Averill, S. J. Van Wyck and A. C. Whalley, J. Org. Chem., 2016, 81, 12001-12005.

11 R. W. Miller, A. K. Duncan, S. T. Schneebeli, D. L. Gray and A. C. Whalley, Chem.-Eur. J., 2014, 20, 3705-3711.

12 Y. Sakamoto and T. Suzuki, J. Am. Chem. Soc., 2013, 135, 14074-14077.

13 K. Y. Cheung, C. K. Chan, Z. Liu and Q. Miao, Angew. Chem., Int. Ed., 2017, 56, 9003-9007.

14 K. Yamamoto, Y. Saitho, D. Iwaki and T. Ooka, Angew. Chem., Int. Ed. Engl., 1991, 30, 1173-1174.

15 K. Y. Cheung, X. Xu and Q. Miao, J. Am. Chem. Soc., 2015, 137, 3910-3914.

16 S. H. Pun, C. K. Chan, J. Luo, Z. Liu and Q. Miao, Angew. Chem., Int. Ed., 2018, 57, 1581-1586.

17 K. Kawasumi, Q. Zhang, Y. Segawa, L. T. Scott and K. Itami, Nat. Chem., 2013, 5, 739-744.

18 K. Kato, Y. Segawa, L. T. Scott and K. Itami, Chem.-Asian J., 2015, 10, 1635-1639.

19 H. A. Lin, Y. Sato, Y. Segawa, T. Nishihara, N. Sugimoto, L. T. Scott, T. Higashiyama and K. Itami, Angew. Chem., Int. Ed., 2018, 57, 2874-2878.

20 X. Xiong, C.-L. Deng, B. F. Minaev, G. V. Baryshnikov, X.-S. Peng and H. N. C. Wong, Chem.-Asian J., 2015, 10, 969-975.

21 S. Kato, Y. Serizawa, D. Sakamaki, S. Seki, Y. Miyake and H. Shinokubo, Chem. Commun., 2015, 51, 1694416947.

22 J. H. Dopper and H. Wynberg, J. Org. Chem., 1975, 40, 19571966.

23 C. Li, Y. Yang and Q. Miao, Chem.-Asian J., 2018, 13, 884894.

24 T. Fujikawa, Y. Segawa and K. Itami, J. Am. Chem. Soc., 2015, 137, 7763-7768.

25 T. Fujikawa, Y. Segawa and K. Itami, J. Am. Chem. Soc., 2016, 138, 3587-3595.

26 T. Fujikawa, Y. Segawa and K. Itami, J. Org. Chem., 2017, 82, 7745-7749.

27 M. Ferreira, G. Naulet, H. Gallardo, P. Dechambenoit, H. Bock and F. Durola, Angew. Chem., Int. Ed., 2017, 56, 3379-3382. 
28 Y. Hu, X.-Y. Wang, P.-X. Peng, X.-C. Wang, X.-Y. Cao, X. Feng, K. Müllen and A. Narita, Angew. Chem., Int. Ed., 2017, 56, 3374-3378.

29 V. Berezhnaia, M. Roy, N. Vanthuyne, M. Villa, J.-V. Naubron, J. Rodriguez, Y. Coquerel and M. Gingras, J. Am. Chem. Soc., 2017, 139, 18508-18511.

30 T. Hosokawa, Y. Takahashi, T. Matsushima, S. Watanabe, S. Kikkawa, I. Azumaya, A. Tsurusaki and K. Kamikawa, J. Am. Chem. Soc., 2017, 139, 18512-18521.

31 Y. Zhu, Z. Xia, Z. Cai, Z. Yuan, N. Jiang, T. Li, Y. Wang, X. Guo, Z. Li, S. Ma, D. Zhong, Y. Li and J. Wang, J. Am. Chem. Soc., 2018, 140, 4222-4226.

32 Y. Shen and C.-F. Chen, Chem. Rev., 2012, 112, 1463-1535.

33 D. Meng, H. Fu, C. Xiao, X. Meng, T. Winands, W. Ma, W. Wei, B. Fan, L. Huo, N. L. Doltsinis, Y. Li, Y. Sun and Z. Wang, J. Am. Chem. Soc., 2016, 138, 10184-10190.

34 M. Ball, Y. Zhong, Y. Wu, C. Schenck, F. Ng, M. Steigerwald, S. Xiao and C. Nuckolls, Acc. Chem. Res., 2015, 48, 267-276.
35 L. Shan, D. Liu, H. Li, X. Xu, B. Shan, J.-B. Xu and Q. Miao, Adv. Mater., 2015, 27, 3418-3423.

36 T. Fujikawa, N. Mitoma, A. Wakamiya, A. Saeki, Y. Segawa and K. Itami, Org. Biomol. Chem., 2017, 15, 4697-4703.

37 M. Gingras, Chem. Soc. Rev., 2013, 42, 1051-1095.

38 K. Kato, Y. Segawa, L. T. Scott and K. Itami, Angew. Chem., Int. Ed., 2018, 57, 1337-1341.

39 M. N. Eliseeva and L. T. Scott, J. Am. Chem. Soc., 2012, 134, 15169-15172.

40 X.-Y. Wang, F.-D. Zhuang, X. Zhou, D.-C. Yang, J.-Y. Wang and J. Pei, J. Mater. Chem. C, 2014, 2, 8152-8161.

41 In contrast, only one $\mathrm{C}-\mathrm{C}$ bond formation was found in the photocyclization of $\mathbf{5}$.

42 W. H. Laarhoven and M. H. de Jong, Recl. Trav. Chim. PaysBas, 1973, 92, 651-657.

43 D. Peña, A. Cobas, D. Pérez, E. Guitián and L. Castedo, Org. Lett., 2000, 2, 1629-1632.

44 H. Saito, A. Uchida and S. Watanabe, J. Org. Chem., 2017, 82, 5663-5668. 